\title{
On designing a pervasive mobile learning platform
}

\author{
Teemu H. Laine ${ }^{\mathrm{a} *}$, Mikko Vinni ${ }^{\mathrm{a}}$, Carolina Islas Sedano ${ }^{\mathrm{a}}$ and Mike Joy ${ }^{\mathrm{b}}$ \\ ${ }^{a}$ School of Computing, Joensuu Campus, University of Eastern Finland, Finland; ${ }^{b}$ Department \\ of Computer Science, University of Warwick, UK
}

(Received 15 January 2009; final version received 10 December 2009)

\begin{abstract}
This article presents the features, design and architecture of the Myst pervasive game platform that has been applied in creating pervasive mobile learning games in various contexts such as science festivals and museums in Finland. Based on our experiences with the development, we draw a set of design principles for creating successfully a pervasive game platform that can be easily ported to various contexts. These principles advocate openness, flexibility, interaction models, connections to the outside world, and participatory design of the game content. In the evaluation part we present preliminary results of tests conducted in Finland at the SciFest 2008 festival in Joensuu and at the Museum of Technology in Helsinki. The results suggest that games built with the Myst platform are particularly suitable for children and young adults, and these games motivate players to interact with the environment and help to learn by discovering new things. The Myst platform has clearly potential for similar success in other environments due to easy portability and extensibility.
\end{abstract}

Keywords: pervasive learning space; mobile learning; pervasive game; design principles; participatory design

\section{Introduction}

Traditionally, computing devices have been confined to a specific location inside a clearly visible physical container. Recent developments in wireless technologies and miniaturisation of components have led to the emergence of pervasive computing devices that are embedded everywhere in the environments surrounding us. Most of these devices are interconnected, thus forming a single context-aware system. Examples of pervasive computing applications in everyday lives include smart buildings, smart homes, smart clothes, smart cars and even smart dust (Warneke et al. 2001). Sensors and mobile technologies form an essential part of pervasive computing systems as they together provide high mobility for users and contextual awareness for the system. Today, pervasive computing is a hot topic in many fields across various disciplines such as mobile computing, artificial intelligence, distributed and embedded systems, agent technologies, communication technologies and human-computer interaction.

Mobile learning, or m-learning, is one of the application areas where pervasive computing has become popular and is currently being intensively researched. In this paper we consider m-learning as learning facilitated by mobile devices such as PDAs

*Corresponding author. Email: teemu.laine@uef.fi 
and mobile phones. The primary aim of m-learning is to provide the users with access to learning environment regardless of time and location. Networked mobile devices allow learners to perform cooperative learning tasks in groups. The emergence of embedded intelligence (e.g. smart tags, sensors) has brought forth new forms of learning that have roots in m-learning, namely pervasive learning (Hundebol and Helms 2006) and ubiquitous learning (Ogata and Yano 2004). Figure 1 illustrates the different types of learning in the domains of mobility and embeddedness. In pervasive learning the roles of intelligent environment and context sensitiveness are emphasised. The physical environment has a central role as it provides context for learning, content for learning, as well as system resources (Laine and Joy 2009). In contrast to ubiquitous learning, pervasive learning is less mobile and more connected to a specific context. Compared with other learning environments such as classrooms or field trips, pervasive learning spaces (PLSs) (also known as pervasive learning environments) provide personal interaction between the learners, the environment and the relevant educational content. Furthermore, in properly designed PLSs, learning materials are delivered in a correct format at the right place in right time. PLSs can be deployed not only in traditional learning contexts but also for example in corporate training settings, museums, exhibitions and tourist attractions.

The Myst platform offers a way to deploy game-based PLSs quickly in different contexts. In this paper we present the features and technical details of the Myst platform. Based on our development experiences, we draw a set of design principles that can be used in designing pervasive mobile games and platforms to be re-used in multiple contexts. Additionally, we present preliminary results from questionnaire-based evaluations of two different games in two environments, namely SciFest 2008 science festival in Joensuu and Museum of Technology in Helsinki.

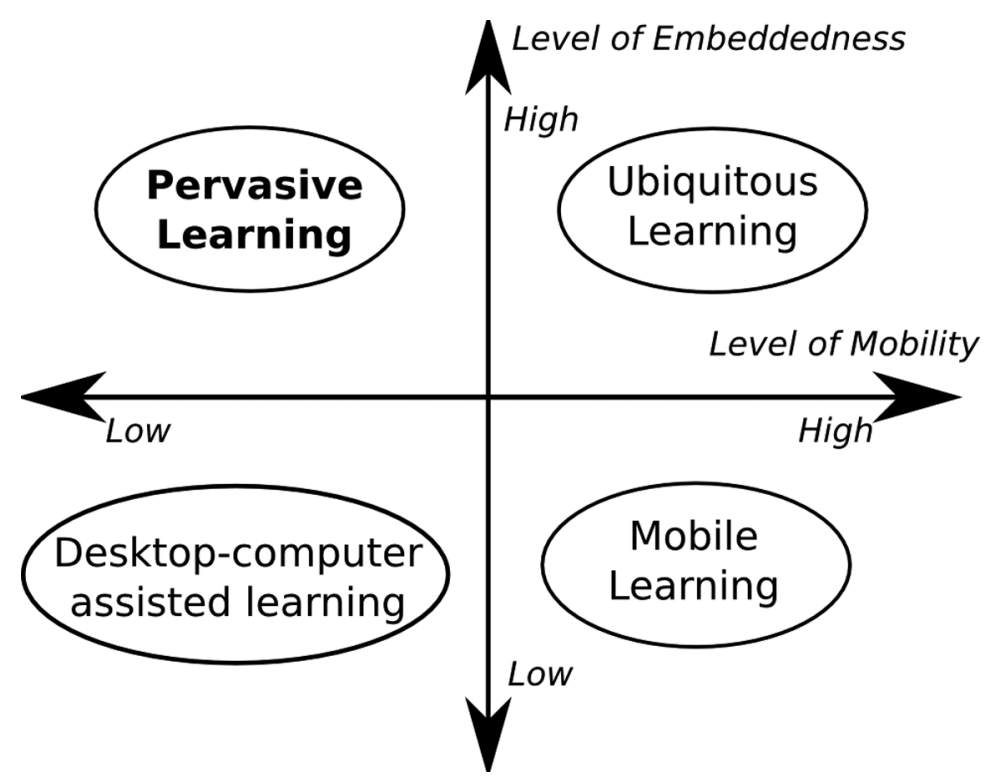

Figure 1. Types of learning.

Source: Lyytinen and Yoo (2002). 


\section{Related work}

Before getting into the details of the Myst platform, we present a representative selection of different PLSs, followed by a discussion of their shortcomings and restrictions. We have intentionally omitted pervasive game environments that do not explicitly present educational agendas.

Beaudin et al. (2007) present a pervasive microlearning system for learning a foreign language in a home environment. In microlearning, a learning task is divided into a series of very quick learning activities. The system has built-in context-awareness through hundreds of wireless sensors and switches embedded in furniture, objects and appliances within the environment. Through this embedded intelligence, the system is able to sense when an object is approached, touched or used. While the system is deeply integrated with the surrounding environment, it is not very portable and does not support group learning activities. Mobile devices are used only for delivering audio information and their other communication features are disabled, thus the interaction potential of those devices is unused.

LORAMS (Link of RFID and Movies System) is a personal learning assistant that supports learners to share and reuse their learning experiences by linking movies and environmental objects (Ogata et al. 2007). Users of LORAMS are equipped with PDA devices coupled to radio-frequency identification (RFID) readers and have wireless local area network (WLAN) connectivity. The key idea of the system is that users record a video of a problem-solving process related to a specific object or phenomenon, and then share that video with other users. Shared videos can be ranked according to relevance, and this ranking information is used in the video search functionality. The system currently supports only a video format that may be proprietary and therefore possibly non-functional with other types of mobile devices. Furthermore, collaboration between users is limited to asynchronous video sharing.

In their work, Lampe and Hinske (2007) present the Augmented Knight's Castle, a pervasive computing playset that enriches children's imaginary play by using background music, sound effects and verbal commentaries on toys that react to children's play. Toys are equipped with audio playback, RFID readers, and a set of sensors such as light meters, accelerometers, and microphones. An RFID-enabled mobile device is in auxiliary role as it can be used to provoke further interaction and to enhance the play. While the Augmented Knight's Castle has a rich set of features and interaction possibilities, it does not provide the true mobility that is often demanded by pervasive applications. Furthermore, the system does not provide any new multi-user features apart from normal children's play.

There have been also instances of pervasive (mobile) learning environments for museums and science exhibitions (for example, Heumer, Gommlich, and Müller 2007; Hsi and Fait 2005; Thom-Santelli et al. 2005). However, most of them are designed for a single purpose and location only, thus lacking the flexibility and portability that the Myst platform offers. The closest match to our work is perhaps the IPerG project (2008), which developed among other tools the multi-user publishing environment (MUPE) for creating multi-user mobile applications. The Myst platform builds on top of MUPE, thus dramatically reducing the amount of programming effort in development.

The aforementioned PLSs are designed to be used within a confined space such as a building. Examples of open-air PLSs covering larger physical areas include Ambient Wood (Rogers et al. 2004), Environmental Detectives (Klopfer and Squire 2008) and 
Insectopia (Peitz, Saarenpää, and Björk 2007). These PLSs are more flexible in terms of physical context but they still lack the flexibility over content matter as they have been designed for a specific purpose only.

From our research into the development of existing pervasive systems, such as the ones described above, we have observed that the flexibility of such systems to be used anywhere, anytime, and by anyone, is still problematic. Most pervasive systems lack several design aspects that would make them more portable and more interactive. Furthermore, the conceptualisation of pervasive systems should include reflection on how to support social dynamics, which might increase collaboration among learners. In order for a PLS to be usable in wider contexts it should have a flexible design, which would allow not only the addition of new features but also easy deployment to various different environments for various purposes. Open protocols and file types increase the openness and therefore flexibility of the system. In the following sections we present the Myst platform, which solves these problems through extensibility and portability.

\section{The Myst platform}

The Myst platform (not to be confused with the commercial Myst game series) offers a way to deploy pervasive m-learning games fast and easily. The following sections describe the platform's features, architecture and examples of current implementations. The terms learner and player are used interchangeably.

So far we have successfully created and tested Myst-based pervasive mobile games at SciFest science festivals (2007-2009) in Joensuu (SciMyst) (Islas Sedano et al. 2007), the Museum of Technology in Helsinki (TekMyst), the Museum of Pielinen in Lieksa (LieksaMyst) (Laine et al. 2009), and high schools in South Africa (UFractions) (Turtiainen et al. 2009). Additionally, we have organised several shortterm demonstrations with this technology, including an introductory game, to the Educational Technology research group at University of Joensuu, a marketing event of ADE Oy (Animations, Designs and Effects) ${ }^{1}$ in Helsinki, and even at a professor's home. Table 1 illustrates the differences between each of these games so as to provide the reader with a hint on the Myst platform's scalability to various contexts and purposes. All in all, the Myst platform is highly flexible and portable virtually to any context offering knowledge to be discovered and shared.

All of these games except UFractions are based on informal learning environments outside schools. This is because we believe that pervasive learning, where the context performs a major role, has the most potential in environments such as museums where every single object or phenomenon has a story to tell. UFractions could be categorised as ubiquitous or mobile learning as it does not have deep relation to the surrounding physical environment. We do not rule out the possibility of using Myst-based games as part of the curriculum (e.g. to learn mathematics or physics in the classroom), but currently there is no evidence to support this idea other than the UFractions evaluation (Turtiainen et al. 2009).

\section{Platform features}

While designing the Myst platform, our core idea was to make a system that could be used in various locations with minimal customisation effort. Therefore the platform offers various game-like features that may or may not be used in applications 
Table 1. Myst-based pervasive mobile games.

\begin{tabular}{|c|c|c|c|}
\hline Game & Genre & Purpose & Elements \\
\hline $\begin{array}{l}\text { SciMyst } \\
\quad(2007-2009)\end{array}$ & $\begin{array}{l}\text { Scientific treasure } \\
\text { hunt }\end{array}$ & $\begin{array}{l}\text { Exploration of the SciFest } \\
\text { science festival and } \\
\text { learning about various } \\
\text { fields of science }\end{array}$ & $\begin{array}{l}\text {-Multiple-choice } \\
\text { questions } \\
\text {-Find-an-object tasks } \\
\text {-Record impressions } \\
\text {-Collaborative battle } \\
\text {-Web site }\end{array}$ \\
\hline $\begin{array}{l}\text { ADEMyst } \\
(2007)\end{array}$ & $\begin{array}{l}\text { Promotional treasure } \\
\text { hunt }\end{array}$ & $\begin{array}{l}\text { Promotion of ADE's } \\
\text { products and services to } \\
\text { their customers }\end{array}$ & $\begin{array}{l}\text {-Multiple choice } \\
\text { questions } \\
\text {-Find-an-object tasks } \\
\text {-Record impressions }\end{array}$ \\
\hline $\begin{array}{r}\text { TekMyst } \\
(2008)\end{array}$ & $\begin{array}{l}\text { Adventure game on } \\
\text { simple machines }\end{array}$ & $\begin{array}{l}\text { Exploration of the } \\
\text { Museum of Technology } \\
\text { and learning about } \\
\text { simple machines }\end{array}$ & $\begin{array}{l}\text {-Multiple-choice } \\
\text { questions } \\
\text {-Multiple skill levels } \\
\text {-Find-an-object tasks } \\
\text {-Record impressions } \\
\text {-Collaborative battle } \\
\text {-Web site }\end{array}$ \\
\hline $\begin{array}{l}\text { LieksaMyst } \\
\text { (2008) }\end{array}$ & $\begin{array}{l}\text { Storytelling } \\
\text { adventure on past } \\
\text { life in authentic } \\
\text { context }\end{array}$ & $\begin{array}{l}\text { Learn how people used to } \\
\text { live by travelling back } \\
\text { in time to meet } \\
\text { characters from the past }\end{array}$ & $\begin{array}{l}\text {-Interaction with past } \\
\text { characters through } \\
\text { story } \\
\text {-Multiple-choice } \\
\text { questions } \\
\text {-Find-an-object tasks } \\
\text {-Alternative story } \\
\text { branches } \\
\text {-Guest book }\end{array}$ \\
\hline $\begin{array}{l}\text { EdTechMyst } \\
\text { (2008) }\end{array}$ & $\begin{array}{l}\text { Treasure hunt on a } \\
\text { research group }\end{array}$ & $\begin{array}{l}\text { Demonstrate educational } \\
\text { technology research } \\
\text { group research at } \\
\text { University of Joensuu }\end{array}$ & $\begin{array}{l}\text {-Multiple-choice } \\
\text { questions } \\
\text {-Find-an-object tasks } \\
\text {-Record impressions } \\
\text {-Collaborative battle } \\
\text {-Web site }\end{array}$ \\
\hline $\begin{array}{l}\text { UFractions } \\
\text { (2009) }\end{array}$ & $\begin{array}{l}\text { Storytelling } \\
\text { mathematics } \\
\text { adventure }\end{array}$ & $\begin{array}{l}\text { Learn fractions and save } \\
\text { leopards by solving } \\
\text { challenges using } \\
\text { fraction sticks }\end{array}$ & $\begin{array}{l}\text {-Interaction with } \\
\text { leopards through } \\
\text { story } \\
\text {-Usage of fraction } \\
\text { sticks } \\
\text {-Multiple-choice } \\
\text { questions } \\
\text {-Open-ended } \\
\text { questions } \\
\text {-Record evidence on } \\
\text { fractions } \\
\text {-Collaborative battle } \\
\text {-Web site }\end{array}$ \\
\hline
\end{tabular}


utilising the platform. These features reach several dimensions of game play through which both players and non-players can experience the surrounding environment. Firstly, the basic game play contains context-sensitive enigmas to be solved by players. These enigmas come with many flavours, ranging from text-based queries to 'take-a-picture' tasks in which the player must locate a certain object or phenomenon based on given description and read a tag attached to it. Tags can be, for example, two-dimensional barcodes or RFID tags. The order of enigmas can be pre-defined, randomised or chosen by the player. Correctly solved enigmas award a number of points to the player, whereas an unsuccessful solving attempt decreases the player's total point score. There is no time limit in solving enigmas in this game mode. If a player needs help with solving an enigma, they can either: read additional hint about related object/phenomenon on the mobile device; ask for help from other players through the multiplayer help feature in the game - the person who provides help is awarded additional points; or ask for more information from a non-player character related to the enigma. Several players can also share one mobile device and play as a team.

Examples of an enigma and related additional information from the SciMyst2008 game are presented in Figures $2 \mathrm{a}$ and $2 \mathrm{~b}$, respectively. The game area can be divided into several areas and each area has a unique set of enigmas related to it. Context awareness is implemented by smart tags (e.g. 2D barcode, RFID) or automatic positioning (e.g. Global Positioning System, WLAN positioning), which can be used to determine location of the player.

Secondly, the Myst platform offers a game mode through which a player can record data through the mobile device's camera, microphone and text input mechanisms. Impressions, as we call the recorded data, are automatically marked with the player's name, a time stamp and the location at which the data were recorded. Enigma information can be also added to the impression if necessary. Each recorded impression awards the player a number of points that are added to player's total score. All impressions are stored in a database and published on a dedicated web site in a gallery. The players can therefore refer to their recordings after the game

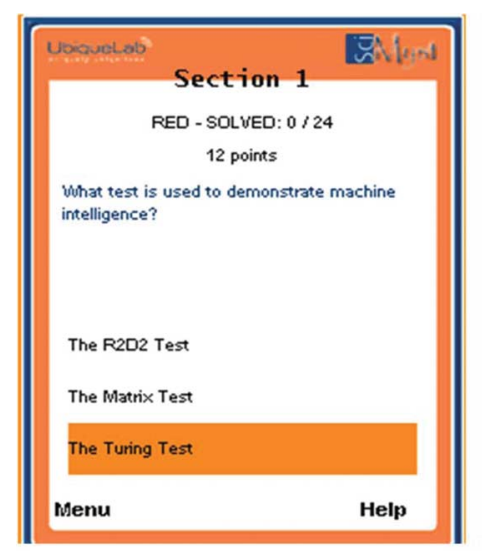

a)

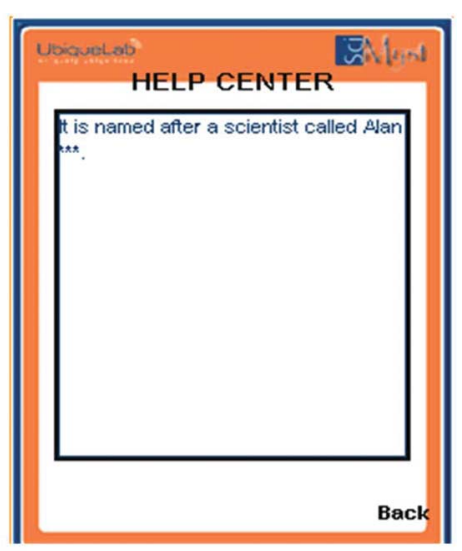

b)

Figure 2. An enigma (a) and a related additional hint (b) in SciMyst2008. 
play has finished and non-players can also experience how others perceived the environment.

Thirdly, the Myst platform has a mode that allows creation of story-based games where enigmas can be embedded inside the storyline. These stories have one or more narrators - either fictional characters or simply the telephone - and the player can interact with these characters through enigmas and story. The story-based game mode may or may not record player's points. Story parts can be linked together and the player can be given a choice to select from various possible branches of the story. In addition to text, stories can contain images, sounds and video. Figure 3 presents excerpts from LieksaMyst game's story including a multiple choice enigma and an enigma where the player has to locate an object to help Anna in her daily chores.

Before finishing the game play, the player may enter the final battle in which he/ she has to solve as many enigmas as possible within a limited amount of time. Additionally, wrong answers will reduce the battle score, thus giving more wrong than correct answers will reduce their total points. The enigmas presented at this stage can be from any area, thus the battle mode works as a refreshing exercise. After finishing the battle, the game may show a digital questionnaire with simple multiple-choice and open questions. This is not part of the actual game play but useful from the research point of view.

Finally, the Myst platform offers synchronous integration between the players' performance and the game's web site. For example, in SciMyst2008 the theme of the game was battle against ignorance. The web site presented statistics of ignorance points that accumulated at a regular rate during three days of the festival. At the same time, the total scores of the players were calculated and displayed in real time against the ignorance points. As a result, the game efforts of all the players were put together to 'fight against ignorance' and this battle could be followed in real time on the game web site. In addition to the interactive battle against ignorance results, the game web site also presented statistics of the performance of individual players including total points, enigma points, battle points, impression points and helping points. In each Myst-based game, the collaborative battle may have a different theme but the underlying technology is the same.

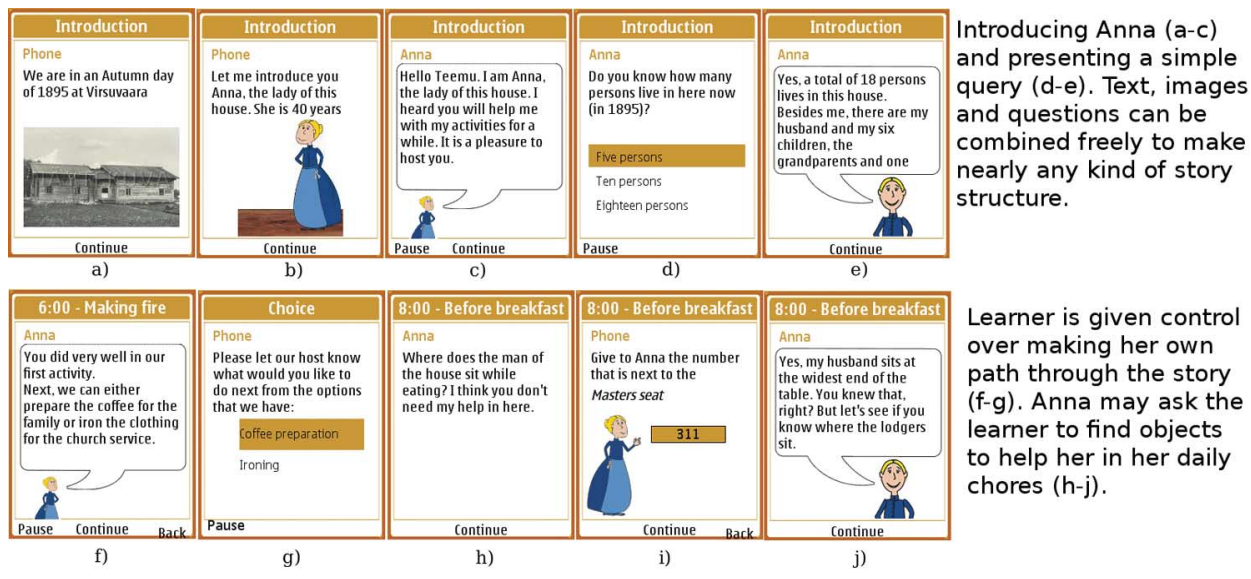

Figure 3. Conversation with Anna in LieksaMyst. 


\section{Design principles}

Development of the Myst platform has been an iterative process that is still ongoing. The process has taught us important lessons on how to design a PLS platform successfully. It must be noted, however, that due to the rapid development of pervasive and mobile technologies, these principles are likely to evolve in the future. One of the most important factors to consider when designing a PLS is the flexibility of design. A flexible design is needed if the system is planned to be used in various contexts with different contents. There are several dimensions of variety that can be tackled with flexible design, including:

- variety of contexts (e.g. physical locations),

- variety of content types (e.g. different media types),

- variety of players (age, gender, language, preferences), and

- variety of interactions between players and non-player characters.

Once the platform can flexibly support these aspects, different applications can be deployed to various environments without the need to redesign the architecture.

As PLSs usually comprise several physically separated components, and communication is required between these components, it is important to use open protocols and portable languages so that individual components can be easily replaced and modified if needed. Openness also allows other developers to contribute to the system by developing extensions and new features. The Myst platform, is built on an open Java/XML-based MUPE platform that utilises the $\mathrm{TCP} / \mathrm{IP}$ protocol in communication. When designing the network, it is important to consider what type of network serves best the system requirements. For example, in a geographically limited urban setting, a WLAN connection is sufficient, while more ubiquitous systems require $3 \mathrm{G}$ connectivity to keep players mobile. There is a trade-off between WLAN and $3 \mathrm{G}$ in terms of range and price; whereas WLAN has shorter range and no data transfer costs, $3 \mathrm{G}$ has larger coverage but fairly expensive data rates in many countries. As the Myst platform is based on the $\mathrm{TCP} / \mathrm{IP}$ protocol, both WLAN and $3 \mathrm{G}$ can be used as long as client devices support them.

Interaction models in learner-learner and learner-system interactions are essential when designing PLSs. It is relevant to take into account how to support social dynamics in pervasive systems to encourage collaboration among learners. One example of the development of social dynamics towards collaboration is an online game environment such as World of Warcraft. The design of the PLS should also take into account the interaction among players (learners) and non-player characters. Hence, it is important to keep in mind the different profiles of players as well as the appropriateness of interaction among players and non-player characters. For example, some non-player characters may not want to be disturbed if they are occupied with something. On the other hand, encouraging shy players to interact with each other is another challenge that remains yet to be resolved.

In order to support the experience and reflection after using the PLS, interaction with the outside world should be considered. Providing the learners with access to learning data after the learning scenario has ended will extend the learning process to locations beyond the actual learning arena. Interaction with the outside world can be implemented in diverse ways, but the easiest and probably the most accessible way is 
to create a web site for the learning environment through which non-player characters as well as learners can access the stored data.

Finally, one important thing to remember when designing a PLS is to design with the stakeholders (as opposed to designing for the stakeholders). In the case of a museum, for example, stakeholders comprises museum visitors, curators, and other content matter experts. In the design process of the Myst platform and games based on it, we have used participatory design methodology with the end-users and frequent design workshops with content matter experts to come up with a finely-tuned game experience for every each context. A word of caution is useful here though: creating motivating and effective content takes a significant amount of time.

\section{Architecture}

Similar to many other PLSs (Laine and Joy 2009), the Myst platform is based on a client-server architecture through Nokia's MUPE system (Nokia Corporation 2008). The fundamental idea behind MUPE is that the server pushes content to the client in XML (eXtensible Markup Language) format, and the client renders the XML to show the corresponding user interface screen on the mobile device. The functionalities of the MUPE client can be extended easily by developing plug-ins. MUPE was chosen as the platform due to its portability and ease of deployment as most of the updates are performed on the server side. As shown in Figure 4, the high-level architecture of the Myst platform can be divided into four distinct interconnected parts - server, clients, pervasive environment, and off-site extension - connected by a wireless LAN or a $3 \mathrm{G}$ network, for instance. In the following sections we will describe each of these components in detail.

\section{Server}

The MUPE server is written in Java and uses an XML-based language to deliver a graphical user interface to client devices running the counterpart MUPE client. A

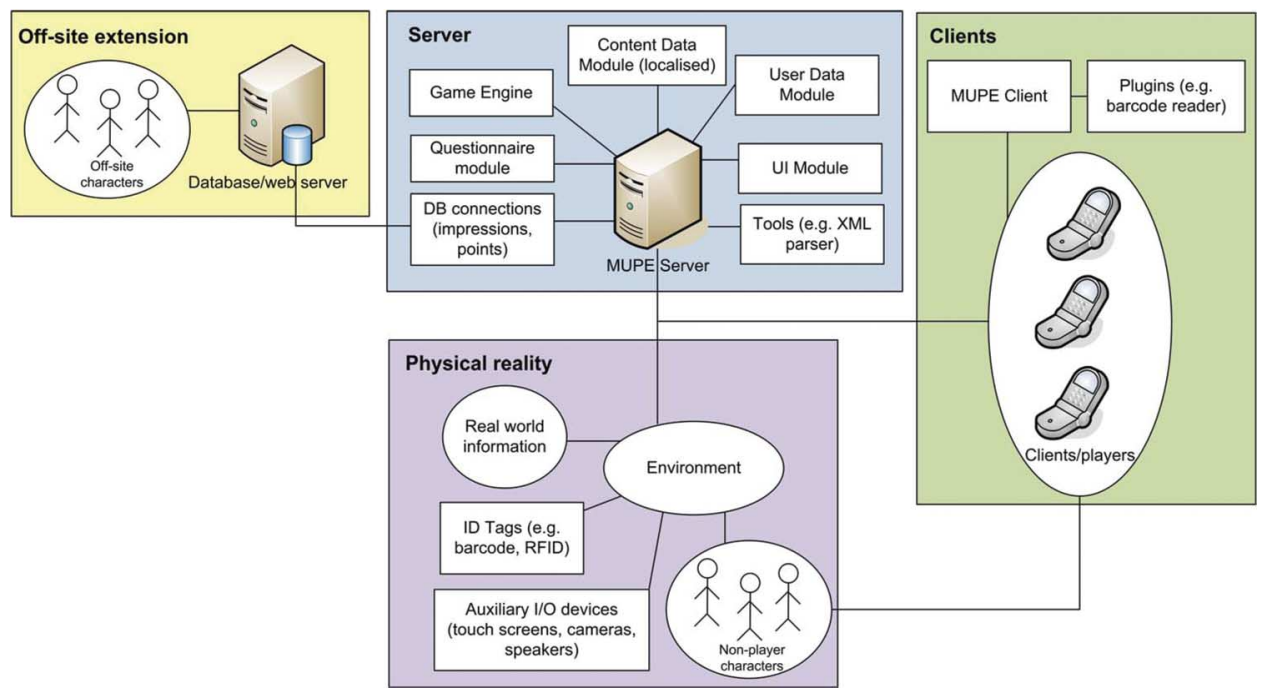

Figure 4. High-level architecture of the Myst platform. 
developer can extend the server by creating their own classes and XML sheets, which provide the actual game dynamics and content. We extended the MUPE server by several modules that provide the necessary data structures, rules, content and tools for pervasive Myst games. The Game Engine coordinates the various software components and also provides a set of game rules (e.g. time constraints and point management) that can be easily modified to fit a specific setting. The Content Data Module is responsible for storing enigmas, location data and other content related to the game play. All content of the game is stored in XML format, and Figure 5 presents examples of an enigma and a location. The game content can be localised to a new language just by translating content of the appropriate XML and resource files - this is a great advantage in international settings.

The User Data module keeps a record of each player's performance by recording attempted enigmas, points, impressions, questionnaire results, and any other activities that a player might do. When the game is over, the module automatically stores player's data into a database using the Off-Site Extension component via a database connections module. Each player's data remains active as long as the server is running and the player has not explicitly finished playing. This means that if the mobile device for some reason crashes, the game can be continued from the point at which the game was before the crash. This is an advantage as mobile devices and networks are still fairly unstable.

The User Interface module consists of XML files that represent different user interface screens on mobile devices. Some of these XML files have dynamic calls to some other modules (such as User Data and Game Engine), which are executed on the client when the sheets are parsed or when a certain operation is performed by the player. Similarly, the server can dynamically change the contents of client-user interfaces. This is one of the strengths of MUPE as it allows flexible manipulation and method invocation on both sides. The basic outlook of the user interface can be changed in the Myst platform by merely creating new background graphics. Other user interface tweaking requires XML editing.

The Questionnaire module is in charge of managing questionnaire questions that are presented to the players at the end of the game session. The intention of the questionnaire module is to aid researchers in the data collection process. Questions are presented in XML format and parsed into Java classes when the server is started. The module supports currently multiple-choice and open questions.

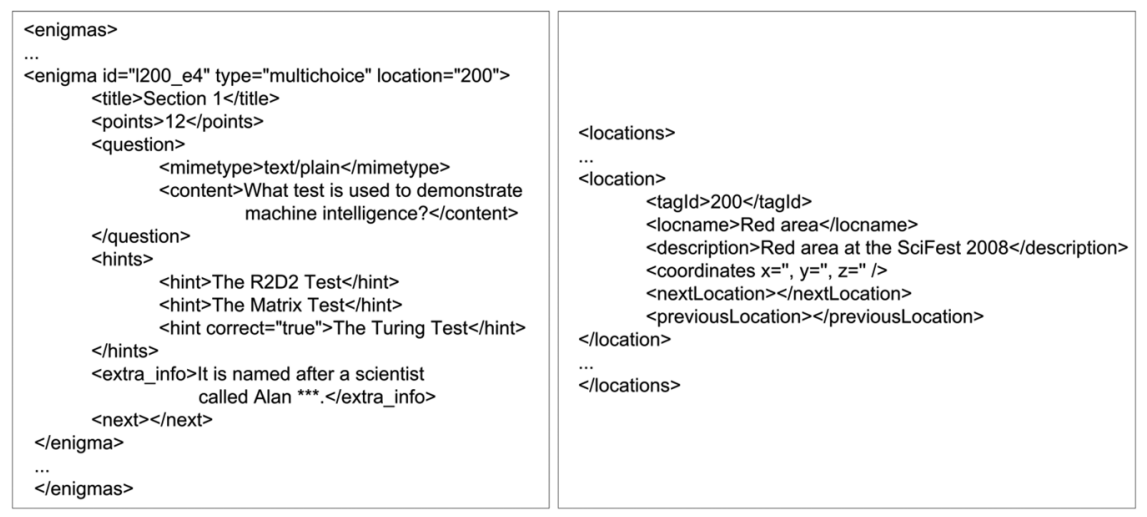

a)

b)

Figure 5. XML representations of an enigma (a) and a location (b). 
The Tools module contains classes for reading and writing files, parsing XML and managing language resources. The $D B$ Connections module is responsible for uploading impressions, players' points and questionnaire results to a MySQL database on the Off-site extension component. The module runs in a separate thread submitting queued jobs to the target database.

\section{Clients}

During the development of the Myst platform we made some changes to the original MUPE client in order to optimise the memory consumption and modify the appearance. Furthermore, we created plug-ins for two-dimensional barcode recognition and near-field communication tag reading in order to support recognition of tagged objects. The client can in theory run on any J2ME-enabled mobile device having a decent amount of processing power and memory. However, we have tested the implemented PLS's only on Nokia N80 and N95 devices.

\section{Pervasive environment}

The game environment has several roles in pervasive games; it contains the game content, it provides a context for the game, and it is also a system resource (Laine and Joy 2009). In games developed on the Myst platform, the environment provides the information from which enigmas are built. This information can be in various formats and it can be represented by an object or a phenomenon. The Myst platform also allows players to capture the environment's information for later reference through the impression recording feature. The game environment is tagged with barcodes or RFID tags through which the system can achieve context awareness. The flexible architecture of the system allows easy deployment of other sensor devices (such as temperature and pressure gauges, accelerometers, light and infrared meters) that can then be used to provide even richer information of the context. Finally, auxiliary devices such as microphones, speakers and (touch)screens embedded in the environment can be used to provide additional I/O capabilities to enrich the communication for the players.

\section{Off-site extension}

The main aim of the Off-site extension is to provide an overview of the actual game play to people located outside the festival arena. Furthermore, it provides the actual players with a 'rear-view mirror' for looking back to their game results and memories (recorded impressions) after finishing the game. The extension is based on a web server supported by PHP and the MySQL database. The Off-site extension stores players' points, impressions and questionnaires in database tables. The web site has usually several sections including, but not limited to, the introductory page, the collaborative battle page, individual scores, and the impression gallery. The collaborative battle page constantly updates and refreshes the status of game using statistical figures and a pie chart. The impression gallery is based on the Pixelpost photograph gallery software, which allows browsing, commenting and management of the images. 


\section{Evaluation}

During the SciFest 2008 event (March 2008) and the first TekMyst test week (August 2008) we conducted surveys with three phases. First, players filled in a pre-game questionnaire that recorded demographic information as well as the players' previous experience in using mobile phones and mobile games. We presented the players with a short introduction to the respective game (SciMyst2008 or TekMyst) and showed them how to read 2D barcodes with a telephone. Then we gave the players (some individually, others in groups of two or three) telephones and area maps, and told them to play freely in all areas as long as they wanted. After returning back, we asked the players to fill in a short questionnaire on the mobile device, and another paper questionnaire having questions unsuitable for answering on a mobile device. In this section, we present the results of the mobile questionnaire from SciMyst2008 and TekMyst, and related part of the paper questionnaire of TekMyst. Questionnaires were chosen as a tool because performing more qualitative data collection (e.g. interviewing) would have been too much for the available resources. Evaluation of TekMyst also involved observations done by researchers and museum curators, but this paper focuses on the questionnaire data.

For SciMyst2008, anyone visiting the SciFest festival could participate in the test. In total, 50 players completed the first part of the paper questionnaire. The age range was between five and 55 years, the mean being between 16 and 20 years old, and $44 \%$ of the players were female while $56 \%$ were male. Some of the players had to finish the game early due to reasons external to the game (such as the school bus leaving), and could not therefore fill in the second part of the paper questionnaire. As a result, only 36 players answered all three questionnaires, and four answered the first and third questionnaires only. Table 2, which is based on the responses to the mobile questionnaire $(n=36)$, presents the statements and answer percentages for each alternative answer - strongly agree (SA), agree (A), disagree (D), strongly disagree (SD) - as well as some basic statistical information. For average and standard deviation calculations we assigned value SA as four points, A as three points, D as two points and $\mathrm{SD}$ as one point. Questionnaires were presented either in English or Finnish depending on the player's preference.

In the TekMyst evaluation at the Museum of Technology in Helsinki, the players were mostly pre-selected school children classes aged between 11 and 16. However,

Table 2. Results of the mobile questionnaire for SciMyst2008.

Statement

SA (\%) A (\%) D (\%) SD (\%) Average \begin{tabular}{c}
$\begin{array}{c}\text { Standard } \\
\text { deviation }\end{array}$ \\
\hline
\end{tabular}

$\begin{array}{lllllll}\text { 1. Interaction with the environment } & 40.00 & 51.43 & 2.86 & 5.71 & 3.35 & 0.75\end{array}$ was exciting

$\begin{array}{lllllll}\text { 2. Game helped me to discover new } & 47.22 & 33.33 & 16.67 & 2.78 & 3.23 & 0.81\end{array}$ things

$\begin{array}{lllllll}\text { 3. I want to play SciMyst with my } & 44.44 & 19.44 & 27.78 & 8.33 & 3.05 & 1.02\end{array}$ own phone

$\begin{array}{lllllll}\text { 4. I want to play SciMyst at other } & 41.67 & 30.56 & 19.44 & 8.33 & 3.16 & 0.95\end{array}$ locations

5. I liked solving enigmas

41.67

$47.22 \quad 5.56$

5.56

3.30

0.77

6. I liked recording impressions of the festival

33.33

41.67

$\begin{array}{lll}13.89 & 11.11 \quad 3.02\end{array}$

0.94 
a few adults and families took also part in the evaluation during one open day. In total, the age range was from eight to 54 and average age was 15.95 . Of all players, $64.8 \%$ were male and $35.2 \%$ female. The procedure was very similar to that of SciMyst 2008 except for test group scheduling, which was more controlled in case of TekMyst; hence we received more complete answers. In total, 55 participants answered the mobile questionnaire thoroughly and the results are presented in Table 3. Table 4 presents results of parts of the paper questionnaire that relate to the questions of the mobile questionnaire. We received in total 111 complete answers to TekMyst's paper questionnaire. The difference between this and the number of mobile questionnaire answers can be explained by the fact that the mobile questionnaire was answered often by a group of two or three players while the paper questionnaire was individual. In addition to the SA, A, D and SD answer options, a 'didn't use it' (DUI) option was also available. DUI answers were left out from average and standard deviation calculations.

These preliminary results suggest that the game was received well in both SciFest 2008 and the Museum of Technology by the players of many ages, most of whom were children or young adults. Interaction with the environment was deemed highly exciting and this shows that well-designed interaction with the environment is an essential part of pervasive learning spaces. As the responses to the second question suggest, both games helped a good majority of players to discover new things about exhibitions in both events. Although many players showed their interest in trying the games with their own telephones, a significant number disagreed. This may be because as the players were mostly children and youngsters, their personal mobile devices may have required features to play such games. However, most players were eager to try the games in other locations; this is a clear indication that the Myst platform could have potential

Table 3. Results of the mobile questionnaire for TekMyst.

\begin{tabular}{lcccccc}
\hline Statement & SA (\%) & A (\%) & D (\%) & SD (\%) & Average & $\begin{array}{c}\text { Standard } \\
\text { deviation }\end{array}$ \\
\hline $\begin{array}{l}\text { 1. Interaction with the environment } \\
\text { was exciting }\end{array}$ & 43.64 & 41.82 & 7.27 & 7.27 & 3.22 & 0.88 \\
$\begin{array}{l}\text { 2. Game helped me to discover new } \\
\text { things }\end{array}$ & 43.64 & 47.27 & 3.64 & 5.45 & 3.29 & 0.79 \\
$\begin{array}{l}\text { 3. I want to play TekMyst with my } \\
\text { own phone }\end{array}$ & 34.55 & 30.91 & 21.82 & 10.91 & 2.87 & 1.04 \\
$\begin{array}{l}\text { 4. I want to play TekMyst at other } \\
\text { locations }\end{array}$ & 50.91 & 29.09 & 10.91 & 9.09 & 3.22 & 0.98 \\
$\begin{array}{l}\text { 5. Answering this questionnaire } \\
\text { with a phone was easy }\end{array}$ & 41.67 & 47.22 & 5.56 & 5.56 & 3.24 & 0.82 \\
\hline
\end{tabular}

Table 4. Results of the related parts of the paper questionnaire for TekMyst.

Standard

Statement $\quad$ SA (\%) A (\%) D (\%) SD (\%) DUI (\%) Average deviation

\begin{tabular}{llllllll}
\hline 6. I liked solving enigmas & 45.95 & 36.04 & 9.91 & 5.41 & 2.7 & 3.26 & 0.86 \\
$\begin{array}{l}\text { 7. I liked recording } \\
\text { impressions of the festival }\end{array}$ & 27.93 & 46.85 & 9.91 & 6.31 & 9.01 & 3.06 & 0.83 \\
$\begin{array}{l}\text { 8. I liked the final battle } \\
\text { 9. I liked helping others }\end{array}$ & 28.83 & 29.73 & 11.71 & 7.21 & 22.52 & 3.03 & 0.95 \\
\hline
\end{tabular}


for other arenas than museums and science exhibitions. In the fifth and sixth questions of SciMyst2008 we measured how the players perceived the two core features of the game - enigma-solving and impression-recording. Same aspects were measured for TekMyst in the paper questionnaire. Particularly, enigma-solving gained much positive attention - and the lower result in impression-recording might be only because not all players tried the feature. In the case of TekMyst, battle and peer-helping features were also somewhat appreciated although a significant part of players did not use them. Additionally, in the TekMyst evaluation we asked the players whether filling the questionnaire on the mobile phone was easy, to see whether we should keep doing it in the future. The results suggest that we indeed should. Overall results of the mobile questionnaire suggest that games built with the Myst platform are suitable for children and young adults and these games motivate players to interact with the environment and help to learn by discovering new things. The Myst platform has clearly potential for similar success in other environments due to easy portability and extensibility.

\section{Conclusions and future work}

In this paper, we have presented the features, architecture and design principles of the Myst platform for pervasive mobile games. The reviewed existing systems lack some or all of the features of the Myst platform: portability, extensibility, open platform support, high interactivity, web-based access and integration with the world outside the playing environment. Based on shortcomings of prior work and our experiences with the development of the Myst platform, we drew up a set of design principles that should be considered when building flexible PLS solutions. In the evaluation of SciMyst2008 and TekMyst, two games implemented on the Myst platform, preliminary results suggest that both games suit children and young adults particularly well; however, the results do not invalidate their effectiveness for older players. Furthermore, the players found interaction with the environment and solving enigmas particularly exciting, and they expressed their interest in playing similar games in other locations as well.

In future, we will continue to develop the Myst platform and apply it in new contexts such as forests and other tourist attractions, in rural and urban locations. The array of existing Myst game genres allows the flexibility to choose from various approaches (e.g. competitive versus non-competitive, story-based versus actionoriented, simulation versus adventure). Naturally we do not rule out the possibility of adopting new genres, such as strategy, in the future. Another strand of future development is to integrate the Myst platform with a mobile sensor gateway, which is currently under development. The aim of the mobile sensor gateway is to use a mobile device to gather and analyse data from a wireless sensor network, in order to increase context-sensitivity and utilisation of the properties and status of the physical environment. Yet another future goal is to develop an editor component that could be used by subject-matter experts or teachers to develop new Myst-based games and content for them. Currently we have an editor component for the LieksaMyst game, but it has been built for the use of museum curators. By adapting its core functionality, we might be able to create a general editor that could be applied to many kinds of Myst-based games. Finally, while this paper presented the technical and design aspects of the Myst platform, we are currently constructing a new model (Laine et al. 2009) for pervasive learning spaces, and in the future the PLSs implemented on the Myst platform will be evaluated against the model. 


\section{Notes}

1. ADE Oy is a company based in Turku, Finland.

\section{References}

Beaudin, J.S., S.S. Intille, Mun E. guia Tapia, R. Rockinson, and M.E. Morris. 2007. Contextsensitive microlearning of foreign language vocabulary on a mobile device. Paper presented at the European Conference on Ambient Intelligence, November, in Darmstadt, Germany.

Heumer, G., F. GommLich, and A. Müller. 2007. Via Mineralia - a pervasive museum exploration game. Paper presented at the PerGames Conference, June 11-12, in Salzburg, Austria.

Hsi, S., and H. Fait. 2005. RFID enhances visitors' museum experience at the exploratorium. Communications of the ACM 46, no. 9: 60-5.

Hundebol, J., and N.H. Helms. 2006. Pervasive learning environments. Paper presented at the Society for Information Technology \& Teacher Education International Conference (AACE), March 20-24, in Orlando, FL, USA.

IPerG Project. 2008. Project website. http://www.pervasive-gaming.org.

Islas Sedano, C., T.H. Laine, M. Vinni, and E. Sutinen. 2007. Where is the answer? The importance of curiosity in pervasive mobile games. In Proceedings of the conference on Future Play, 46-53. New York, NY: ACM Press.

Klopfer, E., and K. Squire. 2008. Environmental detectives - The development of an augmented reality platform for environmental simulations. Educational Technology Research and Development 25, no. 2: 203-28.

Laine, T.H., and M. Joy. 2009. Survey on context-aware pervasive learning environments. International Journal of Interactive Mobile Technologies (I-JIM) 3, no. 1: 70-6.

Laine, T.H., M. Joy, C. Islas Sedano, and M. Vinni. 2009. Characteristics of pervasive learning environments in museum contexts. Paper presented at the MLearn Conference, October 26-30, in Orlando, FL, USA.

Lampe, M., and S. Hinske. 2007. Integrating interactive learning experiences into augmented toy environments. Paper presented at the Pervasive Learning Workshop at the Pervasive Conference, May 13-16, in Toronto, Ontario, Canada.

Lyytinen, K., and Y. Yoo. 2002. Issues and challenges in ubiquitous computing. Communications of $A C M$ 45, no. 12: 62-5.

Nokia Corporation. 2008. Multi-user publishing environment (MUPE). http://www.mupe.net/.

Ogata, H., Y. Matsuka, M. El-Bishouty, and Y. Yano. 2007. LORAMS: Capturing sharing and reusing experiences by linking physical objects and videos. Paper presented at the Pervasive Learning Workshop at the Pervasive Conference, May 13, in Toronto, Ontario, Canada.

Ogata, H., and Y. Yano. 2004. Context-aware support for computer-supported ubiquitous learning. Paper presented at the IEEE International Workshop on Wireless and Mobile Technologies in Education, March 23-25, in Taoyuan, Taiwan.

Peitz, J., H. Saarenpää, and S. Björk. 2007. Insectopia: Exploring pervasive games through technology already pervasively available. Paper presented at the International Conference on Advances in Computer Entertainment Technology, June 13-15, in Salzburg, Austria.

Rogers, Y., S. Price, G. Fitzpatrick, R. Fleck, E. Harris, H. Smith, C. Randell, et al. 2004. Ambient wood: Designing new forms of digital augmentation for learning outdoors. Paper presented at the Conference on Interaction Design and Children: Building A Community, June $1-3$, in College Park, MD, USA.

Thom-Santelli, J., C. Toma, K. Boehner, and G. Gay. 2005. Beyond just the facts: Museum detective guides. Paper presented at the International Workshop of Re-Thinking Technology in Museums: Towards a New Understanding of People's Experience in Museums, June 29-30, in Limerick, Ireland.

Turtiainen, E., S. Blignaut, C. Els, T.H. Laine, and E. Sutinen. 2009. Story-based UFractions mobile game in South Africa: Contextualization process and multidimensional playing experiences. Paper presented at the Second Workshop of Story Telling and Educational Games (STEG 2009), August 21, in Aachen, Germany.

Warneke, B., M. Last, B. Liebowitz, and K.S.J. Pister. 2001. Smart dust: Communicating with a cubic-millimeter. Computer 34, no. 1: 44-51. 